\title{
Ultrafast Dynamics of \\ Quantum Systems
}

Physical Processes and

Spectroscopic Techniques 


\section{NATO ASI Series}

\section{Advanced Science Institutes Series}

A series presenting the results of activities sponsored by the NATO Science Committee, which aims at the dissemination of advanced scientific and technological knowledge, with a view to strengthening links between scientific communities.

The series is published by an international board of publishers in conjunction with the NATO Scientific Affairs Division
A Life Sciences
B Physics
C Mathematical and Physical Sciences
D Behavioral and Social Sciences
E Applied Sciences
F Computer and Systems Sciences
G Ecological Sciences
H Cell Biology
I Global Environmental Change

\section{PARTNERSHIP SUB-SERIES}

1. Disarmament Technologies

2. Environment

3. High Technology

4. Science and Technology Policy

5. Computer Networking
Plenum Publishing Corporation
New York and London

Kluwer Academic Publishers

Dordrecht, Boston, and London

\section{Springer-Verlag}

Berlin, Heidelberg, New York, London,

Paris, Tokyo, Hong Kong, and Barcelona

The Partnership Sub-Series incorporates activities undertaken in collaboration with NATO's Cooperation Partners, the countries of the CIS and Central and Eastern Europe, in Priority Areas of concern to those countries.

\section{Recent Volumes in this Series:}

Volume 369 - Beam Shaping and Control with Nonlinear Optics edited by F. Kajzar and R. Reinisch

Volume 370 - Supersymmetry and Trace Formulae: Chaos and Disorder edited by lgor V. Lemer, Jonathan P. Keating, and David E. Khmelnitskii

Volume 371 - The Gap Symmetry and Fluctuations in High-Tc Superconductors edited by Julien Bok, Guy Deutscher, Davor Pavuna, and Stuart A. Wolf

Volume 372 - Ultrafast Dynamics of Quantum Systems: Physical Processes and Spectroscopic Techniques edited by Baldassare Di Bartolo

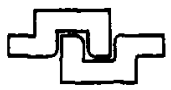

Series B: Physics 


\section{Ultrafast Dynamics of Quantum Systems}

Physical Processes and Spectroscopic Techniques

Edited by Baldassare Di Bartolo

Boston College

Chestnut Hill, Massachusetts

Assistant Editor

Giulio Gambarota

Boston College

Chestnut Hill, Massachusetts

KLUWER ACADEMIC PUBLISHERS

NEW YORK, BOSTON, DORDRECHT, LONDON, MOSCOW 
$\begin{array}{ll}\text { eBook ISBN: } & 0-306-47080-2 \\ \text { Print ISBN: } & 0-306-45929-9\end{array}$

(C)2002 Kluwer Academic Publishers

New York, Boston, Dordrecht, London, Moscow

Print $@ 1998$ Plenum Press

New York

All rights reserved

No part of this eBook may be reproduced or transmitted in any form or by any means, electronic, mechanical, recording, or otherwise, without written consent from the Publisher

Created in the United States of America

Visit Kluwer Online at: and Kluwer's eBookstore at: http://kluweronline.com

http://ebooks.kluweronline.com 
Quel sol che pria d'amor mi scaldò 'I petto Di bella verità m'avea scoverto,

Provando e riprovando, il doce aspetto.

-Dante, Paradiso, III Canto 


\section{PREFACE}

This book presents the Proceedings of the course "Ultrafast Dynamics of Quantum Systems: Physical Processes and Spectroscopic Techniques" held in Erice, Italy from June 15 to June 30, 1997. This meeting was organized by the International School of Atomic and Molecular Spectroscopy of the "Ettore Majorana" Centre for Scientific Culture.

This Institute was devoted to the study of ultrafast physical phenomena, such as nonequilibrium phonon effects, evolution of excitations at surfaces, dynamics of electrons in semiconductors and metals, rapid conformational changes in molecules and optical control of the quantum states of molecules and solids. A total of 74 participants came from 54 laboratories and 14 different countries (the Czech Republic, Denmark, Finland, France, Germany, Italy, The Netherlands, Portugal, Russia, Spain, Switzerland, Turkey, The United Kingdom, and The United States).

The secretaries of the course were Giulio Gambarota and Daniel Di Bartolo.

50 lectures divided in 14 series were given. In addition 9 (one or two-hour) "long seminars," 1 interdisciplinary lecture, 14 "short seminars" and 17 posters were presented. The sequence of the lectures was in accordance with the logical development of the subject of the meeting. Each lecturer started at a rather fundamental level and ultimately reached the frontier of knowledge in the field.

Two round-table discussions were held. The first round-table discussion took place after 4 days of lectures in order to evaluate the work done in the first days of the course and consider suggestions and proposals regarding the organization, format and presentation of the lectures. The second one was held at the conclusion of the course, so that the participants could comment on the work done during the entire meeting and discuss various proposals for the next course of the International School of Atomic and Molecular Spectroscopy.

I wish to express my sincere gratitude to Dr. Alberto Gabriele, and Mr. Pino Aceto and to all the personnel of the "Ettore Majorana" Centre, who contributed to create a congenial atmosphere for our meeting. I wish to acknowledge the sponsorship of the meeting by the NATO Scientific Affairs Division, Boston College, the ENEA Organization, the European Physical Society, the Italian Ministry of Education, the Italian Ministry of University and Scientific Research, and the Sicilian Regional Government.

I wish also to acknowledge the National Science Foundation for providing travel grants for some of our participants.

I would like to thank Ms. Maria Zaini of the Ettore Majorana Centre, the members of the Organizing Committee (Prof. Claus Klingshirn, Dr. Cees Ronda, and Dr. Giuseppe Baldacchini), the secretaries of the course (Giulio Gambarota and Daniel Di Bartolo), Prof. John Collins, Dr. Aliki Collins, Prof. Xuesheng Chen, Ms. Daniela Alba, Mr. Giuseppe Corrao and Dr. Brian Walsh for their valuable help, and Dr. John Di Bartolo for putting the program in the Internet. 
As in the past I felt privileged to direct a NATO Institute, to encounter in my native land of Trapani so many fine people, and to share with them the Erice experience. The meeting of this year provided me with a particularly joyous experience, for I had the singular pleasure and honor to receive all the participants in the house of my family in Trapani, which my brother Francesco has recently restored.

I am already looking forward to the next 1999 meeting of the International School of Atomic and Molecular Spectroscopy, where I am sure I will see again many of you, my friends. Arrivederci a presto!

Baldassare (Rino) Di Bartolo

Director of the International School of Atomic and Molecular Spectroscopy of the "Ettore Majorana" Centre 


\section{CONTENTS}

Linear and Nonlinear Propagation of Short Light Pulses $\ldots \ldots \ldots \ldots \ldots \ldots \ldots \ldots$

B. Di Bartolo

Time Resolved Molecular Spectroscopy and Molecular Dynamics

W. Demtröder, A. Kamal, E. Mehdizadeh, G. Persch, Th. Weyh and D. Zevgolis

Femtosecond Dynamics of Molecular Reactions at Metal Surfaces

R. Finlay and E. Mazur

Some Selected Aspects of Light-Matter Interaction in Solids

C. F. Klingshirn

Femtosecond Pulse Generation: Principles and Fiber Applications

E. P. Ippen

Laser Sources for Ultrafast Spectroscopy

A. I. Ferguson

Phonons and Electron-Phonons Interaction in Semiconductors and High-Tc

Superconductors

M. Cardona

Surface Phonons and Their Role in Ultrafast Phenomena

G. Benedek

Dielectric Description of Matter: From Maxwell- to Semiconductor Bloch-Equations .. 323 R. v. Baltz

Coherent Dynamics in Semiconductors J. Hvam

Quasiparticles and Quasimomentum

R. v. Baltz and C. Klingshirn

On the Equivalence of Coupled Pendula and Quantum Mechanical Non-Crossing Rule

A. Jolk, C. F. Klingshirn, and R. v. Baltz

Ultrafast Optical Spectroscopy and Optical Control

T. F.Crimmins, R. M. Koehl, K. A. Nelson 


\section{LONG SEMINARS}

Solitons in Optical Fibers and Application to High Bit Rate Transmission 487

L. Mollenauer

Hot Luminescence and Fast Relaxation of Optical Centers in Solids

G. Baldacchini

Jahn-Teller Driven Movements of Excited Ions in Crystals

C. Ronda

Recent Results in Multiphonon Non-Radiative Processes and in Novel Materials and Amplifiers

F. Auzel

NASA’s DIAL/Lidar Laser Technology Development Program

J. Barnes

Applications of Ultrafast Spectroscopy to Solid State Laser Materials

J. Collins

Ultrafast Electron-Lattice Relaxation of Optically Excited Centers in Crystals 569

N. Terzi and M. Dominoni

Laser Crystal Emitting from UV to IR and the Impact of Nonlinear Optics

G. Boulon

Nonperturbative Upconversion Techniques: Ultrafast Meets X-ray

C. Schaffer

Nonlinear Interactions in Insulating Laser Crystals under Femtosecond and Picosecond Excitation

A. Kaminskii

\section{INTERDISCIPLINARY LECTURE}

Unification in Particle Physics: Symmetries and Hidden Dimensions

G. Costa

\section{SHORT SEMINARS}

Measurements with an Optically Gated Scanning Tunneling Microscope 673

J. R. Jensen

Time Resolved Spectroscopy of Deep Emissions from Large Band Gap

Semiconductors

R. Seitz

Chemical Dynamics of Uni- and Bimolecular Reactions Studied with Non-Linear

Optical Techniques in the Femtosecond Time Domain

M. Motzkus 
Fluorescence Intensity and Anisotropy Decay Measurements in the Frequency

Domain

F. De Matteis

Non-Destructive Optical Characterization of $\ln _{x} \mathrm{Ga}_{1-x}$ As Epitaxial Layer

Composition Thickness and Optical Quality

X. Chen

Optical Homogeneous Linewidth in Amorphous Solids in the Framework of the Soft Potential Model

A. Garcia Adeva

Raman Shifted Laser Crystals with $\chi^{3}$ Nonlinearity: Tungstate and Molybdate

Crystal Families

F. Bourgeois

Luminescence Quantum Efficiency in CdSSe Mixed Crystals

R. Westphaeling

Luminescence and Afterglow in CsI:Tl

H. Wieczorek

Position Sensitive Time of Flight Spectrometry of Molecules

J. Larsen

Probing Exciton Distributions in Semiconductor Quantum Layers

J. Hoffmann

Light Induced Molecular Structure in $\mathrm{H}_{2}^{+}$ K. Saendig

\section{POSTERS}

Time Resolved Spin Relaxation in III-V Semiconductor Quantum Wells

R. Britton

Analysis of the $4 \mathrm{f}^{\mathrm{N}}$ Energy Level Structure of the $\mathrm{RE}^{3+}$ Ions in RE Oxyhalides 688

R. J. Lamminmäki

Temperature Dependence of Near Infrared to Visible Upconversion Luminescence of $\mathrm{Er}^{3+}$ in YSGG

X. Chen

Quantum Confinement in Porous Silicon in the Effective-Mass Limit

I. H. Libon 
Ultrashort Laser Pulses Measurements by Means of Self Diffraction in

Polydispersed Liquid Crystals

A. Mazzulla

Optical Near-Field Measurements on a Single Gold Nanoparticle

T. Klar

Single-Atom Conditional Manipulation of Confined Quantized Electromagnetic

Field

A. Napoli

Iterative Nonideal Conditional Generation of Nonclassical Cavity Field

A. Napoli

Multiple Branching of Vectorial Spatial Solitary Waves in Nonlinear Quadratic

Media

G.Leo

Relaxation Dynamics of Localized Excitons in ZnSe-ZnSSe Strained-Layer Superlattices

M. Netti

Identification of Several Energy Transfer Pathways in the Light-Harvesting Complex II of Green Plants Using Current Structural and Spectroscopic Information

S. Ozdemir

Transient and Persistent Spectral Hole-Burning in $\mathrm{CuBr}$ Semiconductor Quantum

Dots

J. Valenta

Multiphoton Excitation of GaN Using Picosecond Pulses

C. Voelkmann

$0.94 \mu \mathrm{m}$ Spectroscopy and Laser Development

B. Walsh

Spectral Lineshapes of Ammonia Transitions of the $v_{2}$ Band versus Pressure and Temperature

F. Pelagalli

Multiphoton Excited Luminescence of Porous Silicon

C. Voelkmann

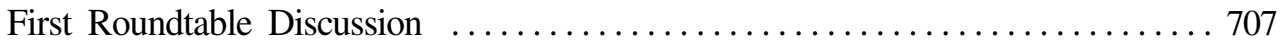

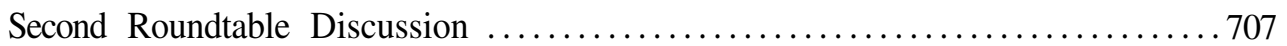

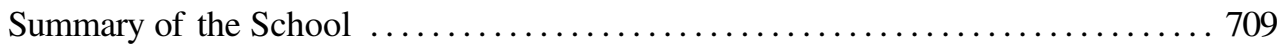

K. A. Nelson

Participants

Index 


\section{Ultrafast Dynamics of Quantum Systems}

Physical Processes and

Spectroscopic Techniques 